\title{
Obesity and COVID-19: Time to Take Action
}

\author{
Feray Akbas Hanife Usta Atmaca \\ Department of Internal Medicine, Istanbul Training and Research Hospital, University of \\ Health Sciences, Istanbul, Turkey
}

\section{Dear Editor,}

We have read with great interest the European Association for the Study of Obesity (EASO) Position Statement on the Global COVID-19 Pandemic, which emphasized the importance of evidence-based information and guidance to meet the healthcare needs of patients with obesity who have been affected by coronavirus disease 2019 (COVID-19).

COVID-19 has affected more than 3.5 million people globally up to the present [1]. Although it did affect a great diversity of people all around the world, several accompanying diseases were highlighted for the majority of people who were hospitalized with the disease.

In preliminary reports from China, the most common co-morbidities in patients who were infected with COVID-19 were type 2 diabetes, hypertension, chronic obstructive pulmonary disease, chronic renal disease, hepatitis B, coronary heart disease, cerebrovascular disease, and immunodeficiency [2]. Obesity was not mentioned as a common co-morbidity of COVID-19 infection, which was later attributed to the lower rates of obesity seen in far-east cultures. Similarly, obesity was not listed among clinical determinants for fatality, either. Age, gender, severity of illness, and co-morbidities such as hypertension, type 2 diabetes, cardiovascular disease, respiratory disease, and cancer were major factors distinguished between survivors and non-survivors of COVID-19 [3].

Then, body mass index (BMI) was the target of attention as severely ill patients were found to have a higher BMI than non-severely ill patients [4], and unfavorable outcomes were reported among COVID-19 patients with obesity [5, 6].

We know that visceral adiposity acts like an immune organ and causes low-grade chronic inflammation [7]. When it is combined with hyperinflammation and "cytokine storm" as seen in COVID-19, increased morbidity for people with obesity seems to be unavoidable [8]. Chronic inflammation can lead to persistent infections, and microbiota changes in obesity

\section{Karger $\stackrel{2}{*}$}


might contribute to this situation. The defective immune system in obesity creates susceptibility to infections, including viral infections. In fact, several adipogenic viruses have been described, and obesity-associated immune suppression might play a key role for the prognosis of viral infections seen in people with obesity [9].

Several other mechanisms are suggested to explain the poor outcomes in concomitance of obesity and COVID-19 infection, such as altered adipose tissue hormones, complement components, vasculature, and alveolus. It is also hypothesized that insulin resistance, but not fat mass, could be responsible for poor COVID-19 outcomes in patients with obesity [10].

On the other hand, obesity-related diseases such as type 2 diabetes, hypertension, hyperlipidemia, cardiovascular, and cerebrovascular diseases are also sources of concern in COVID-19 infection prognosis and concomitant with obesity, they may increase the severity of the disease [11].

Thrombotic incidents are common in COVID-19 patients and chronic inflammation and impaired fibrinolysis that underlie the thrombosis seen in obesity might cause increased thromboembolism risk in this population $[12,13]$.

Increased weight is also associated with the development of acute respiratory distress syndrome, especially in patients with severe obesity (BMI $>40 \mathrm{~kg} / \mathrm{m}^{2}$ ). Both obesity and acute respiratory distress syndrome appear to have alterations in inflammation, endothelial dysfunction, and oxidative stress, which increase the risk for respiratory failure $[14,15]$. Decreased pulmonary capacity in obesity facilitates the need for mechanical ventilation, and intensive care unit admissions are increased among critical COVID-19 patients with obesity $[16,17]$.

Additionally, obesity is a risk factor for hospital admissions in younger COVID-19 patients. Although patients who are younger than 60 years old are accepted to have a lower risk for COVID-19 disease severity, younger populations are expected to be affected more than previously reported in populations with a high prevalence of obesity $[18,19]$.

The immune system and metabolic state are both major determinants for survival of COVID-19 infection, and as we summarized here, people with obesity present frailty by those means. Thus, as clarified in the position statement of EASO, it is vital to consider the needs of individuals living with obesity during the COVID-19 pandemic and take all precautions needed for this vulnerable group to decrease the morbidity and mortality.

\section{Conflict of Interest Statement}

The authors have no conflicts of interest to declare.

\section{Author Contributions}

All authors listed have contributed sufficiently to the paper to be included as authors.

\section{References}

1 WHO. Coronavirus disease (COVID-19) Situation Report-107: Data as received by WHO from national authorities by 10:00 CEST, 6 May 2020. Available from: https://www.who.int/docs/default-source/coronaviruse/ situation-reports/20200506covid-19-sitrep-107.pdf?sfvrsn=159c3dc_2 (accessed May 7, 2020).

2 Guan WJ, Ni ZY, Hu Y, Liang WH, Ou CQ, He JX, et al.; China Medical Treatment Expert Group for Covid-19. Clinical Characteristics of Coronavirus Disease 2019 in China. N Engl J Med. 2020 Apr;382(18):1708-20.

3 Deng G, Yin M, Chen X, Zeng F. Clinical determinants for fatality of 44,672 patients with COVID-19. Crit Care. 2020 Apr;24(1):179.

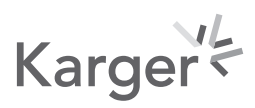


4 Chen Q, Zheng Z, Zhang C, Zhang X, Wu H, Wang J, et al. Clinical characteristics of 145 patients with corona virus disease 2019 (COVID-19) in Taizhou, Zhejiang, China. Infection. 2020 Aug;48(4):543-51.

5 Qingxian C, Fengjuan C, Fang L, Xiaohui L, Tao W, Qikai W, et al. Obesity and COVID-19 Severity in a Designated Hospital in Shenzhen, China. SSRN Electronic Journal 2020. http://dx.doi.org/https://doi.org/10.2139/ ssrn.3556658.

6 Goyal P, Choi JJ, Pinheiro LC, Schenck EJ, Chen R, Jabri A, et al. Clinical Characteristics of Covid-19 in New York City. N Engl J Med. 2020 Jun;382(24):2372-4.

7 Soysal P, Arik F, Smith L, Jackson SE, Isik AT. Inflammation, Frailty and Cardiovascular Disease. Adv Exp Med Biol. 2020;1216:55-64.

8 Tufan A, Avanoğlu Güler A, Matucci-Cerinic M. COVID-19, immune system response, hyperinflammation and repurposing antirheumatic drugs. Turk J Med Sci. 2020 Apr;50 SI-1:620-32.

9 Tian Y, Jennings J, Gong Y, Sang Y. Viral Infections and Interferons in the Development of Obesity. Biomolecules. 2019 Nov;9(11):726.

10 Lockhart SM, O'Rahilly S. When Two Pandemics Meet: Why Is Obesity Associated with Increased COVID-19 Mortality? Med (N Y). 2020 Jun 29. Available from: https://www.ncbi.nlm.nih.gov/pmc/articles/ PMC7323660/.

$11 \mathrm{Hu}$ L, Chen S, Fu Y, Gao Z, Long H, Wang JM, et al. Risk Factors Associated with Clinical Outcomes in 323 COVID-19 Hospitalized Patients in Wuhan, China. Clin Infect Dis. 2020 May;ciaa539.

12 Middeldorp S, Coppens M, van Haaps TF, Foppen M, Vlaar AP, Müller MC, et al. Incidence of venous thromboembolism in hospitalized patients with COVID-19. J Thromb Haemost. 2020 Aug;18(8):1995-2002.

13 Blokhin IO, Lentz SR. Mechanisms of thrombosis in obesity. Curr Opin Hematol. 2013 Sep;20(5):437-44.

14 McCallister JW, Adkins EJ, O’Brien JM Jr. Obesity and acute lung injury. Clin Chest Med. 2009 Sep;30(3):495508.

15 Gong MN, Bajwa EK, Thompson BT, Christiani DC. Body mass index is associated with the development of acute respiratory distress syndrome. Thorax. 2010 Jan;65(1):44-50.

16 Simonnet A, Chetboun M, Poissy J, Raverdy V, Noulette J, Duhamel A, et al.; LICORN and the Lille COVID-19 and Obesity study group. High prevalence of obesity in severe acute respiratory syndrome coronavirus-2 (SARS-CoV-2) requiring invasive mechanical ventilation. Obesity (Silver Spring). 2020 Jul;28(7): 1195-9.

17 Kalligeros M, Shehadeh F, Mylona EK, Benitez G, Beckwith CG, Chan PA, et al. Association of Obesity with Disease Severity Among Patients with Coronavirus Disease 2019. Obesity (Silver Spring). 2020 Jul;28(7): 1200-4.

18 Kass DA, Duggal P, Cingolani O. Obesity could shift severe COVID-19 disease to younger ages. Lancet. 2020 May;395(10236):1544-5.

19 Lighter J, Phillips M, Hochman S, Sterling S, Johnson D, Francois F, et al. Obesity in patients younger than 60 years is a risk factor for Covid-19 hospital admission. Clin Infect Dis. 2020 Jul;71(15):896-7.

\section{Karger ${ }^{\prime}=$}

